\title{
1992-2015年鼎湖山季风常绿阔叶林群落结构动态
}

\author{
邹 顺 ${ }^{1,2}$ 周国逸 张倩媚 $1^{*}$ 徐 姗 ${ }^{1}$ 熊 釒金 ${ }^{1,2}$ 夏艳菊 ${ }^{1,2}$ 刘世忠 ${ }^{1}$ 孟 泽 ${ }^{1}$ \\ 褚国伟 1
}

${ }^{1}$ 中国科学院华南植物园, 广州 $510650{ }^{2}{ }^{2}$ 国科学院大学, 北京 100049

摘 要 季风常绿阔叶林是中国南亚热带地区的地带性植被, 其群落结构及其动态变化直接影响着该森林能为该地区提供 的生态系统服务功能质量。该文利用1992-2015年共24年的长期定点监测数据, 从群落种类组成、生物量、径级、密度等数 量特征方面研究了鼎湖山季风常绿阔叶林群落结构的动态变化。结果表明: 1)到2015年该森林群落林分个体密度增加了 $42.7 \%$, 总生物量减少了 $5.1 \% ; 24$ 年间基于生物量的 $\beta$ 多样性指数群落差异为 $37.4 \%$, 基于个体数的差异则高达 $65.6 \%$; 2)灌木 和小乔木的个体数剧增, 生物量增大, 中乔木和大乔木的个体数变化虽不显著, 但生物量显著降低; 3)小径级(胸径 $<15 \mathrm{~cm})$ 个 体数呈显著增加趋势, 其他径级个体数也有显著变化, 但各径级生物量变化基本不显著; 4)香楠(Aidia canthioides)、鼎湖血桐 (Macaranga sampsonii)、柏拉木(Blastus cochinchinensis)等物种个体数急剧增加, 锥(Castanopsis chinensis)、木荷(Schima superba)、黄果厚壳桂(Cryptocarya concinna) 等树种生物量大量减少, 白颜树 (Gironniera subaequalis)、窄叶半枫荷 (Pterospermum lanceifolium) 等树种生物量增加, 这些物种是群落结构变化的主要贡献者。鼎湖山季风常绿阔叶林群落结构在 1992-2015年发生了巨大变化, 与演替、虫害和气候变化等影响有关。

关键词 林分密度; 生物量; 多样性; 长期; 季风常绿阔叶林

邹顺, 周国逸, 张倩婮, 徐姍, 熊金, 夏艳菊, 刘世忠, 孟泽, 褚国伟 (2018). 1992-2015年鼎湖山季风常绿阔叶林群落结构动态. 植物生态学报, 42, 442-452. DOI: $10.17521 /$ cjpe.2017.0171

\section{Long-term (1992-2015) dynamics of community composition and structure in a monsoon evergreen broad-leaved forest in Dinghushan Biosphere Reserve}

ZOU Shun $^{1,2}$, ZHOU Guo-Yi ${ }^{1}$, ZHANG Qian-Mei ${ }^{1 *}$, XU Shan ${ }^{1}$, XIONG Xin ${ }^{1,2}$, XIA Yan-Ju ${ }^{1,2}$, LIU Shi-Zhong ${ }^{1}$, MENG $\mathrm{Ze}^{1}$, and CHU Guo-Wei ${ }^{1}$

${ }^{1}$ South China Botanical Garden, Chinese Academy of Sciences, Guangzhou 510650, China; and ${ }^{2}$ University of Chinese Academy of Sciences, Beijing 100049, China

\section{Abstract}

Aims The monsoon evergreen broad-leaved forest (MEBF) is the dominant vegetation type in the subtropics of Eurasian continent. It provides vital ecosystem services and supports the socioeconomic development of the societies. Recent literature indicated that the MEBF had been greatly affected by the changing climate and other disturbances such as outbreaks of insects and, consequently, shifted its species composition and structure. In this study, we aim at the long-term changes of plant species and community structure in the MEBF.

Methods Species names, diameters at breast height $(D B H)$, and tree heights of all trees with $D B H \geq 1.0 \mathrm{~cm}$ were recorded in 1992, 1994, 1999, 2004, 2008, 2010 and 2015 in a 1-hm² monitoring plot in the Dinghushan Biosphere Reserve. We quantified the long-term changes over this 24 -year study period by species composition, biological diversity, aboveground biomass, $D B H$ frequency table, and stand density by species.

Important findings From 1992 to 2015, the stand density increased by 42.7\% while the total biomass decreased by $5.1 \%$. The $\beta$ diversity based on biomass and stand density indicated that the diversity increased by $37.4 \%$ and $65.6 \%$, respectively, from 1992 to 2015. More importantly, the number of small arbor and shrubs, and smaller trees $(D B H<15 \mathrm{~cm})$ also increased sharply, with major contributions from Aidia canthioides, Macaranga sampsonii and Blastus cochinchinensis. In contrast, the change in stand biomass was more from biomass decrease of Castanopsis chinensis, Schima superba and Cryptocarya concinna, but increase of Gironniera subaequalis and

收稿日期Received: 2017-06-29 接受日期Accepted: 2018-02-11

基金项目: 国家自然科学基金(41430529)和中国科学院前沿科学重点研究项目(QYZDJ-SSW-DQC003)。Supported by the National Natural Science Foundation of China (41430529), and the Key Research Program of the Chinese Academy of Sciences (QYZDJ-SSW-DQC003).

* 通信作者Corresponding author(zqm@scib.ac.cn) 
Pterospermum lanceifolium. We conclude that the changes on community composition and structure in the MEBF were significant, which was resulted from a combined influence of succession, changes in climate, and insect outbreaks.

Key words stand density; biomass; diversity; long term; monsoon evergreen broad-leaved forest

Zou S, Zhou GY, Zhang QM, Xu S, Xiong X, Xia YJ, Liu SZ, Meng Z, Chu GW (2018). Long-term (1992-2015) dynamics of community composition and structure in a monsoon evergreen broad-leaved forest in Dinghushan Biosphere Reserve. Chinese Journal of Plant Ecology, 42, 442-452. DOI: 10.17521/cjpe.2017.0171

森林具有调节气候、涵养水源、碳固存、生物 多样性保育等不可替代的生态系统功能和服务功能 (肖强等, 2014; Trumbore et al., 2015), 尤其在全球 $\mathrm{CO}_{2}$ 浓度持续上升、地表平均温度增加、降水格局 改变等环境变化背景下, 森林的巨大碳汇功能及其 在减缓气候变化中的作用显得愈加重要(Pan et al., 2011)。森林生态系统的这些功能都受森林群落结构 的强烈影响, 例如群落径级结构及其多样性与群落 生产力呈正相关关系(Zhang \& Chen, 2015), 并影响 森林生态系统碳固存和物质周转速率(Xiao et al., 2014); 森林群落结构影响森林遭受干扰时的抵抗 能力和干扰过后的恢复能力(Jayakaran et al., 2014); 群落结构变化后还常常引起森林产水量和集水区溪 水来源组成的改变(Jayakaran et al., 2014; Wehner \& Stednick, 2017)。

森林群落结构是指树木个体在环境中的分布及 其与周围环境之间相互作用所形成的组分和构造, 包括个体密度、生物量大小、物种-多度分布、径级 结构等(宋永昌, 2001)。演替、自然干扰、气候条件 变化等都能改变群落结构。演替和自然干扰一直是 森林生态学的重要内容, 演替理论认为自然条件下 的森林都有向其顶极状态演替的趋势, 并伴随着群 落结构的变化, 例如个体密度增大、生物量增加、 物种组成改变及物种多样性提高等(Guariguata \& Ostertag, 2001); 而极端气候事件、虫害、火灾等自 然干扰能够短时间改变群落结构或引起群落结构的 根本性变化(Anderegg et al., 2015; Frank et al., 2015); 而近10年来, 全球环境变化, 尤其是气候条件变化 对森林群落结构影响的问题成为研究热点, Allen等 (2015)认为气候变化引起了包括北方森林、温带森 林和热带森林的全球不同类型森林群落结构的变化, 并且气候变化对森林内不同物种和不同径级个体的 影响大小不同(Bennett et al., 2015; Anderegg et al., 2016)。由于森林群落结构及其影响因素的复杂性, 群落结构的长期定点监测仍是我们了解森林群落结
构变化的主要方法(Allen et al., 2010)。

季风常绿阔叶林是中国南亚热带地区的地带性 植被, 该类型森林面积广阔, 物种多样性高(宋永昌 等, 2001; 丁圣彦和宋永昌, 2004)。同时, 该地区也 是人口稠密地区, 季风常绿阔叶林的功能直接关系 该地区的生态安全。在 20 世纪, 彭少麟等人对该地 区季风常绿阔叶林群落的群落结构及其演替趋势做 了较多研究 (王伯荪和彭少麟, 1985; 彭少麟和方炜, 1995; 彭少麟等, 1998; 彭少麟和李丹, 1999), 但近 年来对该森林群落结构动态的长期监测研究较少 (张咏梅等, 2003; 叶万辉等, 2008)。有研究表明, 过 去几十年该地区升高的年平均温度和愈加极端的降 雨格局已经引起土壤湿度的持续下降(Zhou et al., 2011); 该地区同时还是全球三大高氮沉降区域之 一和受酸雨严重影响的区域(Fang et al., 2011)。这些 因素都可能引起该区域森林群落结构的变化。因此, 本文利用1992-2015年鼎湖山季风常绿阔叶林 $1 \mathrm{hm}^{2}$ 永久样地 7 次群落调查数据, 分析不同调查时间点 群落的个体数和生物量总量及组成, 并结合多样性 指数方法, 探究我国南亚热带无人为干扰的近演替 顶极森林群落结构随时间的演变, 为在全球变化背 景下该地区自然林的评估和管理提供科学依据。

\section{1 材料和方法}

\section{1 研究区样地概况}

鼎湖山国家级自然保护区 $\left(23.16^{\circ}-23.19^{\circ} \mathrm{N}\right.$, $\left.112.51^{\circ}-112.56^{\circ} \mathrm{E}\right)$ 位于广东省肇庆市鼎湖区，总占 地面积 $1155 \mathrm{hm}^{2}$, 主要地形为丘陵和低山, 海拔 100-700 m, 最高峰鸡笼山海拔 $1000.3 \mathrm{~m}$ (熊金等, 2016)。该地区属于南亚热带季风气候, 年降水量为 $1714 \mathrm{~mm}$, 年平均湿度为 $76 \%, 4-9$ 月为湿季，10月 到次年3月为旱季，湿季降水量约占 $80 \%$, 干湿季分 明。年平均气温为 $22.5{ }^{\circ} \mathrm{C}$, 最冷月 (1月)和最热月 $(7$ 月)平均气温分别为 $13.8{ }^{\circ} \mathrm{C}$ 和 $28.8{ }^{\circ} \mathrm{C}$; 地质基础主 要为泥盆纪砂岩、砂页岩、页岩和石英砂岩, 地带 
性土壤为南亚热带赤红壤(Zhou et al., 2013), 自然 酸化严重, 土壤的水浸 $\mathrm{pH}$ 值约为 3.7 。

鼎湖山自然保护区的季风常绿阔叶林(以下简 称季风林，MEBF)主要分布于核心区三宝峰，海拔 100-490 m, 具有400多年的保护历史, 属于近演替 顶极阶段(熊金等, 2016)。该群落终年常绿，郁闭度 约 $95 \%$ 。乔木层郁闭度约 $80 \%$ ，可分为两个亚层: 第 一亚层为锥 (Castanopsis chinensis)、木荷 (Schima superba)、黄果厚壳桂(Cryptocarya concinna)、厚壳 桂 (Cryptocarya chinensis)、白颜 树 (Gironniera subaequalis) 等; 第二亚层为鼎湖血桐 (Macaranga sampsonii)、香楠(Aidia canthioides)等。灌木层盖度 约 $50 \%$, 优势种为柏拉木(Blastus cochinchinensis)。 草本层盖度约 $40 \%$, 优势种为华山姜 (Alpinia $o b$ longifolia)等。样地位于低山中坡, 坡度 $25^{\circ}-35^{\circ}$, 土 层厚度为30-90 cm (黄忠良等, 1998)。

\section{2 研究方法}

\subsection{1 样地设置与调查}

鼎湖山季风林永久样地投影面积为 $1 \mathrm{hm}^{2}$ 。样地 采用全站仪将 $10000 \mathrm{~m}^{2}$ 划分为 25 个 $20 \mathrm{~m} \times 20 \mathrm{~m}$ 的 样方, 每个 $20 \mathrm{~m} \times 20 \mathrm{~m}$ 样方用插值法细分为 4 个 $10 \mathrm{~m} \times 10 \mathrm{~m}$ 的样方, 每个 $10 \mathrm{~m} \times 10 \mathrm{~m}$ 样方细划为 4 个 $5 \mathrm{~m} \times 5 \mathrm{~m}$ 的小样方。在1992-2015年间, 共进行了 7次群落调查, 记录样地内所有胸径 $(D B H)$ 大于等于 $1.0 \mathrm{~cm}$ 个体的物种名、胸径、高度、坐标及生长状 况等信息(张咏梅等, 2003)。

\subsection{2 生物量估算}

每个个体生物量由生物量方程(温达志等, 1997) 估算, 并进而计算各物种、生活型和径级的生物量。

\subsection{3 生活型分类}

基于生活型分类系统把群落物种分为两类: 生 活型I为中乔木和大乔木, 在季风林群落内成熟个 体高度大于等于 $8 \mathrm{~m}$, 占据冠层位置, 生活型II为小 乔木和灌木, 在季风林群落内成熟个体高度小于 8 $\mathrm{m}$ (宋永昌, 2001)。

\subsection{4 多样性指数计算}

$\alpha$ 多样性指群落的物种多样性, 是群落内物种 丰富度和物种多度格局的综合体现, 常用于度量群 落物种多样性的大小。 $\alpha$ 多样性指数非常多, 但各指 数具有较强的相关性, 本文采用常用的ShannonWiener指数计算群落的 $\alpha$ 多样性(陈廷贵和张金屯, 1999)。
长时间的群落结构和多样性的变化可以区分为 群落总量(总个体数、总生物量)的变化和群落内物 种个体数或生物量分配的变化。为了描述群落结构 的变化, 以及区分上述两种原因的贡献, 我们分别 计算了以下 4 个相互关联的指数: 分别描述群落间 相似性、差异性的相似指数 $(S I)$ 和 $\beta$ 多样性指数 $(B I)$, 描述群落内物种个体数或生物量分配变化的替换指 数 $(R I)$, 以及描述群落总量变化的总量差异指数 $(D I)$ (Fekete et al., 2017)。

$$
\begin{aligned}
S I_{1992 j}= & \sum_{i=1}^{n} \min \left\{x_{1992 i}, x_{j i}\right\} / \sum_{i=1}^{n} \max \left\{x_{1992 i}, x_{j i}\right\} \\
R I_{1992 j}= & \left(\sum_{i=1}^{n}\left|x_{1992 i}-x_{j i}\right|-\left|\sum_{i=1}^{n} x_{1992 i}-\sum_{i=1}^{n} x_{j i}\right|\right) / \\
& \sum_{i=1}^{n} \max \left\{x_{1992 i}, x_{j i}\right\} \\
D I_{1992 j}= & \left|\sum_{i=1}^{n} x_{1992 i}-\sum_{i=1}^{n} x_{j i}\right| / \sum_{i=1}^{n} \max \left\{x_{1992 i}, x_{j i}\right\}
\end{aligned}
$$

其中, $x_{j i}$ 表示第 $j$ 年 $(j=1994,1999,2004,2008,2010$ 和2015)第 $i$ 个物种的个体数或生物量。 $S I_{1992 j} 、 R I_{1992 j}$ 和 $D I_{1992 j}$ 分别表示第 $j$ 年时群落与 1992 年群落之间的 相似指数、替换指数和总量差异指数。而 $\beta$ 多样性 指数与相似指数, 以及与替换指数和总量差异指数 之间有如下关系, 其中 $B I_{1992 j}$ 表示第 $j$ 年时群落与 1992年群落之间的 $\beta$ 多样性指数。

$$
\begin{aligned}
B I_{1992 j} & =R I_{1992 j}+D I_{1992 j} \\
& =\sum_{i=1}^{n}\left|x_{1992 i}-x_{j i}\right| / \sum_{i=1}^{n} \max \left\{x_{1992 i}, x_{j i}\right\} \\
B I_{1992 j} & +S I_{1992 j}=1
\end{aligned}
$$

\subsection{5 重要值与群落主要物种}

采用重要值 ( (相对多度+相对显著度+相对频 度) /3) 表征物种在群落中的优势程度 (叶万辉等, 2008)。分别计算各次调查各物种的重要值, 如果某 物种 7 次群落调查中出现过至少 1 次物种重要值 $\geqslant 1.0$, 则我们认为它是群落中的主要物种。鼎湖山 季风林有 29 种主要物种(表1), 其重要值、个体数和生 物量之和在群落中的比例分别达 $88 \%$ 、 $87 \%$ 和 $96 \%$ 。

\section{2 结果}

\section{1 群落个体数和生物量总体变化趋势}

1992-2015年样地个体数先略微下降, 在 2004 
年以后急剧上升, 个体数总体呈显著上升趋势 $\left(R^{2}=\right.$ $0.63, p=0.02), 2015$ 年样地总个体数为 5682 个, 是 1992年的1.43倍, 净增个体数为 1701 个(图1A)。群 落物种-多度格局改变, 优势种个体数急剧增加(图 $2 \mathrm{~A}$ ), 其在群落中所占比例增大(图2B), 基于个体数 的群落Shannon-Wiener指数先上升后下降(表2)。随 着时间变化, 各调查年群落与 1992 年群落间的 $\beta$ 多 样性指数 $B I$ (基于个体数)持续增大(Logistic拟合, $R^{2}$ $=0.99, p<0.001)$, 其中替换指数 $R I$ 所占比例都大于 总量差异指数DI (1994年除外)(图3A)。

1992-2015年, 样地生物量呈显著下降趋势 $\left(R^{2}=0.64, p<0.01\right), 2015$ 年样地总生物量为 $278.1 \mathrm{t}$,
比1992年减少了 $15.0 \mathrm{t}$, 下降了 $5.1 \%$ (图1B)。群落物 种-生物量格局改变, 优势种生物量降低(图2C), 其 在群落中所占比例减少(图2D), 导致了基于生物量 的群落Shannon-Wiener指数上升 $(p=0.05)$ (表2)。随 着时间变化, 各调查年群落与 1992 年群落间的 $\beta$ 多 样性指数 $B I$ (基于生物量)持续增大(线性拟合, $R^{2}=$ $0.99, p<0.001)$, 其中总量差异指数DI所占比例都 大于替换指数 $R I$ (1994年除外)(图3B)。

\section{2 群落生活型组成变化}

由图1A所示, 中乔木和大乔木的个体数无显著 变化 $(p>0.05)$; 小乔木和灌木的个体数总体呈显著 增加趋势 $\left(R^{2}=0.72, p<0.01\right), 2015$ 年群落小乔木和

表1 鼎湖山季风林样地群落主要物种 $(I V \geqslant 1.0)$

Table 1 Main species $(I V \geqslant 1.0)$ in the monsoon evergreen broad-leaved forest

\begin{tabular}{|c|c|c|c|c|c|c|c|}
\hline $\begin{array}{l}\text { 序号 } \\
\text { Order }\end{array}$ & $\begin{array}{l}\text { 物种 } \\
\text { Species }\end{array}$ & $\begin{array}{l}\text { 生活型 } \\
\text { Life form }\end{array}$ & $\begin{array}{l}\text { 物种代码 } \\
\text { Species code }\end{array}$ & $\begin{array}{l}\text { 序号 } \\
\text { Order }\end{array}$ & $\begin{array}{l}\text { 物种 } \\
\text { Species }\end{array}$ & $\begin{array}{l}\text { 生活型 } \\
\text { Life form }\end{array}$ & $\begin{array}{l}\text { 物种代码 } \\
\text { Species code }\end{array}$ \\
\hline 1 & 雉 Castanopsis chinensis & I & Cch & 16 & 笔罗子 Meliosma rigida & I & $\mathrm{Mr}$ \\
\hline 2 & 白颜树 Gironniera subaequalis & I & Gs & 17 & 广东金叶子 Craibiodendron scleranthum & I & Cs \\
\hline 3 & 肖蒲桃 Syzygium acuminatissimum & I & $\mathrm{Sa}$ & 18 & 香楠 Aidia canthioides & II & Ac \\
\hline 4 & 木荷 Schima superba & I & Ss & 19 & 鼎湖血桐 Macaranga sampsonii & II & Ms \\
\hline 5 & 窄叶半枫荷 Pterospermum lanceifolium & I & $\mathrm{Pl}$ & 20 & 柏拉木 Blastus cochinchinensis & II & $\mathrm{Bc}$ \\
\hline 6 & 厚壳桂 Cryptocarya chinensis & I & $\mathrm{Crc}$ & 21 & 云南银柴 Aporosa yunnanensis & II & Ay \\
\hline 7 & 橄榄 Canarium album & I & $\mathrm{Ca}$ & 22 & 褐叶柄果木 Mischocarpus pentapetalus & II & Mip \\
\hline 8 & 白楸 Mallotus paniculatus & I & Map & 23 & 红枝蒲桃 Syzygium rehderianum & II & $\mathrm{Sr}$ \\
\hline 9 & 黄果厚壳桂 Cryptocarya concinna & I & Cco & 24 & 光叶红豆 Ormosia glaberrima & II & $\mathrm{Og}$ \\
\hline 10 & 臀果木 Pygeum topengii & I & $\mathrm{Pt}$ & 25 & 黄叶树 Xanthophyllum hainanense & II & $\mathrm{Xh}$ \\
\hline 11 & 肉实树 Sarcosperma laurinum & I & $\mathrm{S} 1$ & 26 & 罗伞树 Ardisia quinquegona & II & $\mathrm{Aq}$ \\
\hline 12 & 观光木 Michelia odora & I & Mo & 27 & 黄毛榕 Ficus esquiroliana & II & $\mathrm{Fe}$ \\
\hline 13 & 华润楠 Machilus chinensis & I & $\mathrm{Mc}$ & 28 & 鼎湖钓樟 Lindera chunii & II & $\mathrm{Lc}$ \\
\hline 14 & 鹅掌柴 Schefflera heptaphylla & I & $\mathrm{Sh}$ & 29 & 九节 Psychotria asiatica & II & $\mathrm{Pa}$ \\
\hline 15 & 黄杞 Engelhardia roxburghiana & I & $\mathrm{Er}$ & & & & \\
\hline
\end{tabular}

$I V$, 重要值。

$I V$, important value.

表2 鼎湖山季风林群落(胸径 $\geqslant 1.0 \mathrm{~cm}$ )物种数以及分别基于多度和生物量的Shannon-Wiener指数变化

Table 2 Changes of species richness and Shannon-Wiener indices based on the individual and biomass from 1992 to 2015 in the $1 \mathrm{hm}^{2}$ monsoon evergreen broad-leaved forest sample plot. All trees with diameters at breast height $\geqslant 1.0 \mathrm{~cm}$ were monitored during the study period

\begin{tabular}{|c|c|c|c|c|c|c|c|}
\hline \multirow{2}{*}{$\begin{array}{l}\text { 年 } \\
\text { Year }\end{array}$} & \multirow{2}{*}{$\begin{array}{l}\text { 物种数 } \\
\text { Species richness }\end{array}$} & \multicolumn{3}{|c|}{ 基于个体数 Individual based } & \multicolumn{3}{|c|}{ 基于生物量 Biomass based } \\
\hline & & $\begin{array}{c}\text { 群落 } \\
\text { Population }\end{array}$ & $\begin{array}{c}\text { 生活型I } \\
\text { Life form I }\end{array}$ & $\begin{array}{c}\text { 生活型II } \\
\text { Life form II }\end{array}$ & $\begin{array}{c}\text { 群落 } \\
\text { Population }\end{array}$ & $\begin{array}{c}\text { 生活型I } \\
\text { Life form I }\end{array}$ & $\begin{array}{l}\text { 生活型II } \\
\text { Life form II }\end{array}$ \\
\hline 1992 & 86 & 2.90 & 2.39 & 2.30 & 2.16 & 1.86 & 2.17 \\
\hline 1994 & 86 & 2.90 & 2.40 & 2.29 & 2.19 & 1.88 & 2.20 \\
\hline 1999 & 90 & 2.99 & 2.52 & 2.39 & 2.27 & 1.97 & 2.21 \\
\hline 2004 & 94 & 3.07 & 2.63 & 2.53 & 2.16 & 1.82 & 2.29 \\
\hline 2008 & 90 & 2.98 & 2.62 & 2.42 & 2.22 & 1.88 & 2.50 \\
\hline 2010 & 90 & 2.91 & 2.64 & 2.34 & 2.30 & 1.93 & 2.49 \\
\hline 2015 & 80 & 2.71 & 2.62 & 2.15 & 2.38 & 2.01 & 2.41 \\
\hline$p$ & $>0.05$ & $>0.05$ & $<0.05$ & $>0.05$ & $=0.05$ & $>0.05$ & $<0.05$ \\
\hline
\end{tabular}



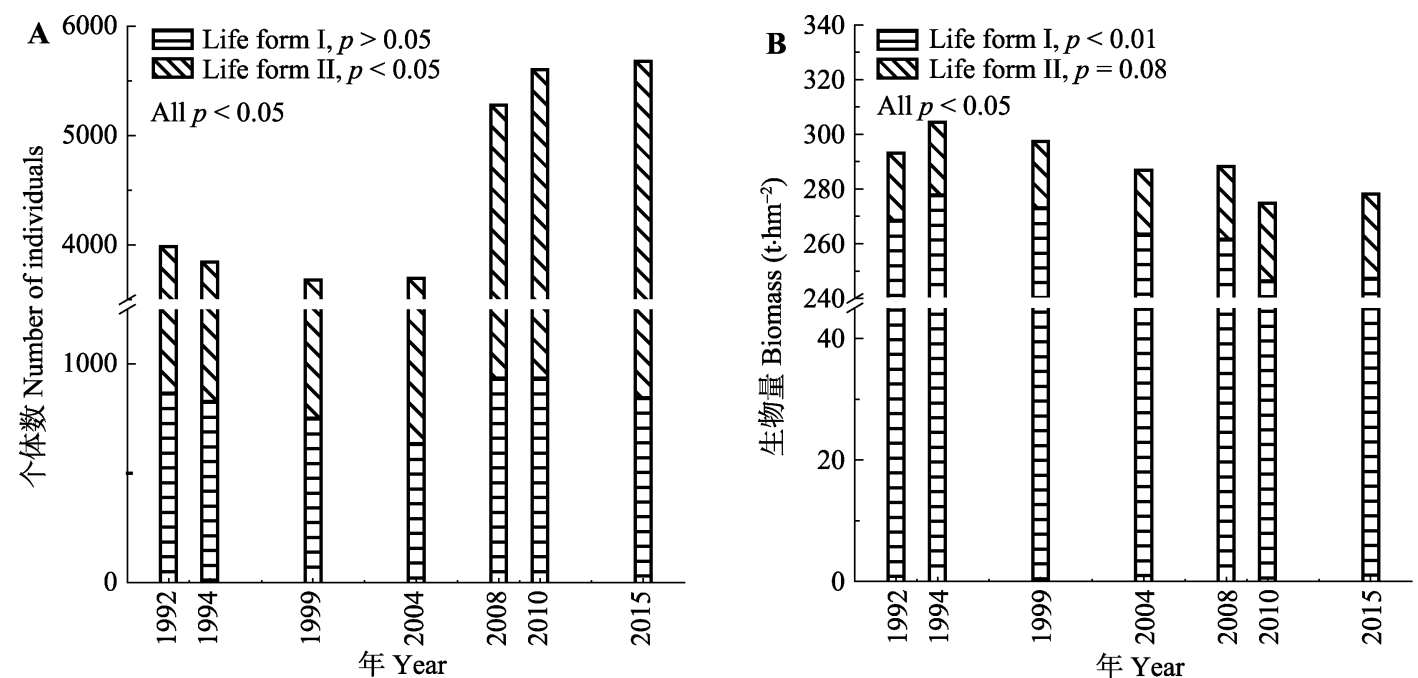

图1 1992-2015年鼎湖山季风林 $1 \mathrm{hm}^{2}$ 样地整个群落(All)、大乔木和中乔木(Life form I)、小乔木和灌木(Life form II)个体数(A) 和生物量 $(\mathbf{B})$ 变化(线性拟合)。

Fig. 1 Changes in stand density (A) and biomass (B) of community (All), middle and big arbor (Life form I) and small arbor and shrub (Life form II) in the $1 \mathrm{hm}^{2}$ monsoon evergreen broad-leaved forest sample plot between 1992 and 2015 (linear fitting).
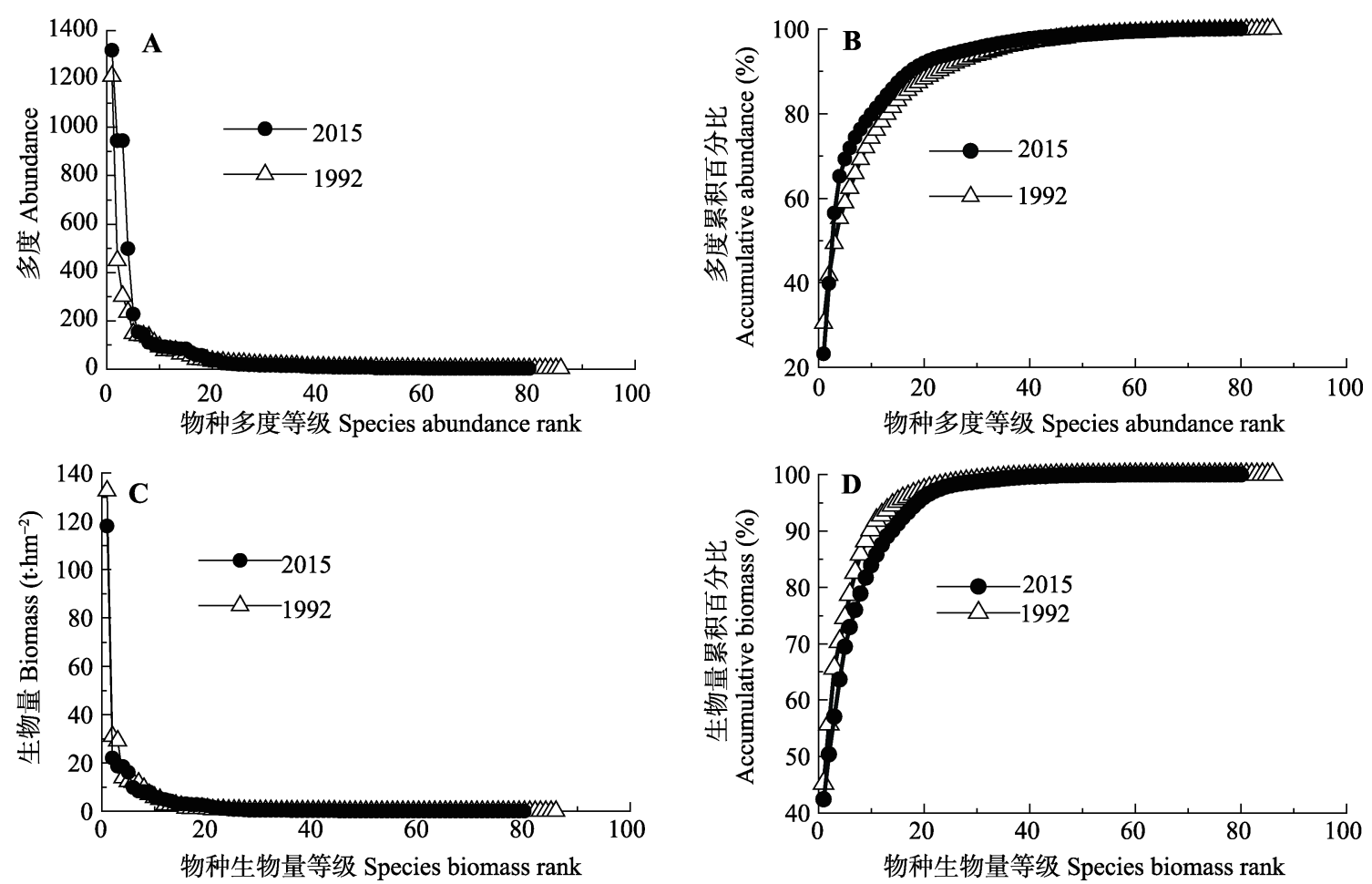

图2 鼎湖山季风林 $1 \mathrm{hm}^{2}$ 样地物种-个体数和物种-生物量格局变化。 $\mathbf{A}$, 物种-多度分布。 $\mathbf{B}$, 物种-多度累积。 C, 物种-生物量 分布。D, 物种-生物量累积。

Fig. 2 Changes in species-abundance and species-biomass relationships in the $1 \mathrm{hm}^{2}$ monsoon evergreen broad-leaved forest sample plot. A, species-abundance distribution. B, accumulative species-abundance. C, species-biomass distribution. D, species-biomass accumulation.

灌木个体数4 836个，与1992年相比增加 1723 个，占 群落个体数净增量的 $101.3 \%$, 导致小乔木和灌木个 体数在群落所占比例增大, 由 1992 年的 $74.4 \%$ 上升 到 2015 年的 $82.3 \%$ 。而基于个体数的中乔木和大乔
木Shannon-Wiener指数显著上升 $(p<0.05)$, 小乔木 和灌木先上升后下降(表2)。

由图1B可见，中乔木和大乔木总生物量呈显著 下降趋势 $\left(R^{2}=0.73, p<0.01\right)$, 与1992年相比, 2015

www.plant-ecology.com 
年群落大乔木和中乔木生物量减少了 $21.1 \mathrm{t}$; 小乔 木和灌木生物量 $\left(R^{2}=0.37, p=0.08\right)$ 有增加趋势, 但 变化在 $\alpha=0.05$ 的置信水平下不显著, 与 1992 年相 比, 其生物量增加了 $6.1 \mathrm{t}$ 。基于生物量的中乔木和 大乔木Shannon-Wiener指数增大, 但趋势不显著 $(p$ $>0.05)$, 而小乔木和灌木Shannon-Wiener指数呈显 著增加趋势 $(p<0.05)$ (表 2$)$ 。

\section{3 群落径级结构变化}

由图4可见，1992-2015年群落DBH $<15 \mathrm{~cm}$ $\left(R^{2}=0.60, p<0.05\right)$ 和 $D B H 35-50 \mathrm{~cm}\left(R^{2}=0.59, p<\right.$ $0.05)$ 径级个体数呈增加趋势, $D B H$ 在 $15-35 \mathrm{~cm}\left(R^{2}=\right.$ $0.43, p=0.06)$ 和 $D B H \geqslant 50 \mathrm{~cm}\left(R^{2}=0.88, p<0.05\right)$
径级个体数呈减小趋势; 群落 $D B H$ 在 $15-35 \mathrm{~cm}$ 径级 生物量显著下降 $\left(R^{2}=0.57, p<0.05\right)$, 而其他径级生 物量没有显著变化趋势。

\section{4 主要物种个体数和生物量变化}

与 1992 年比较, 到 2015 年, 群落中 29 个主要物 种中的 17 个中乔木和大乔木树种中只有 3 个个体数 增量(增加量或减少量)绝对值超过1992年群落总个 体数 $1.0 \%$, 包括厚壳桂、白楸(Mallotus paniculatus) 和黄果厚壳桂, 其中, 厚壳桂和白楸个体数分别增 加了 51 和 80 个, 种群增大 1.6 倍和 16 倍, 黄果厚壳桂 个体数减少 213 个, 种群减小 $70.8 \%$; 这样的小乔木 和灌木树种有 7 个(共 12 个), 包括香楠、鼎湖血桐、柏
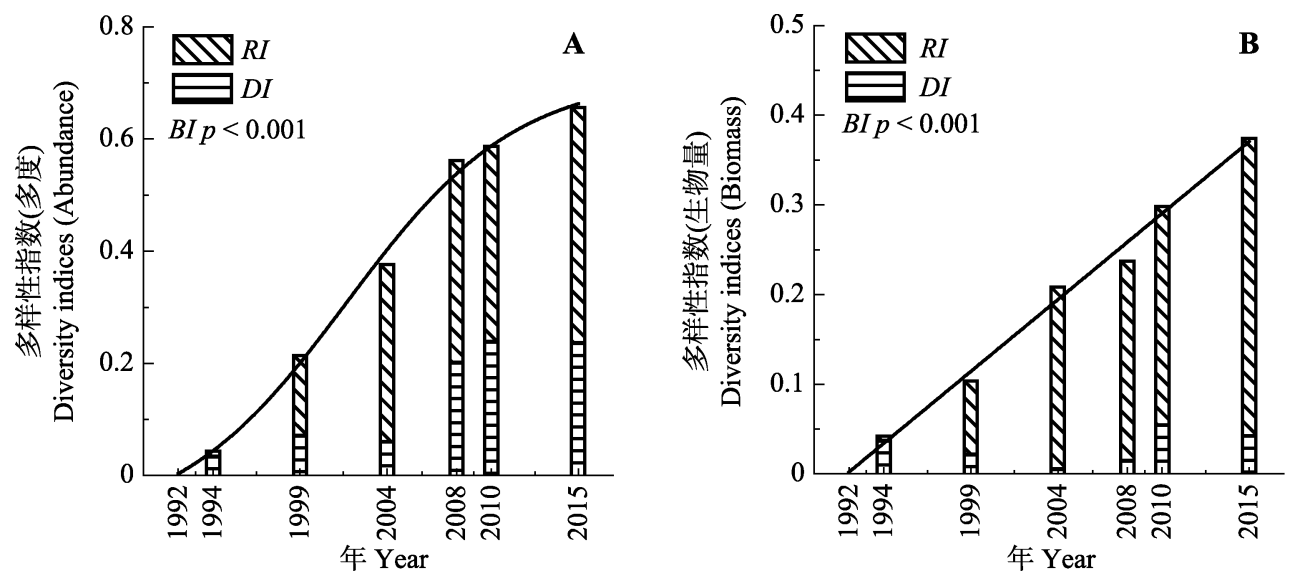

图3 1992-2015年群落替换指数 $(R I)$ 、总量差异指数 $(D I)$ 和 $\beta$ 多样性指数 $(B I)$ 变化。 $\mathbf{A}$, 基于多度(Logistic拟合)。 $\mathbf{B}$, 基于生物 量(线性拟合)。

Fig. 3 Changes in the replacement index (RI), difference index (DI) and $\beta$ diversity index (BI) with year from 1992 to 2015 . A, Abundance-based logistic fitting. B, Biomass-based linear fitting.
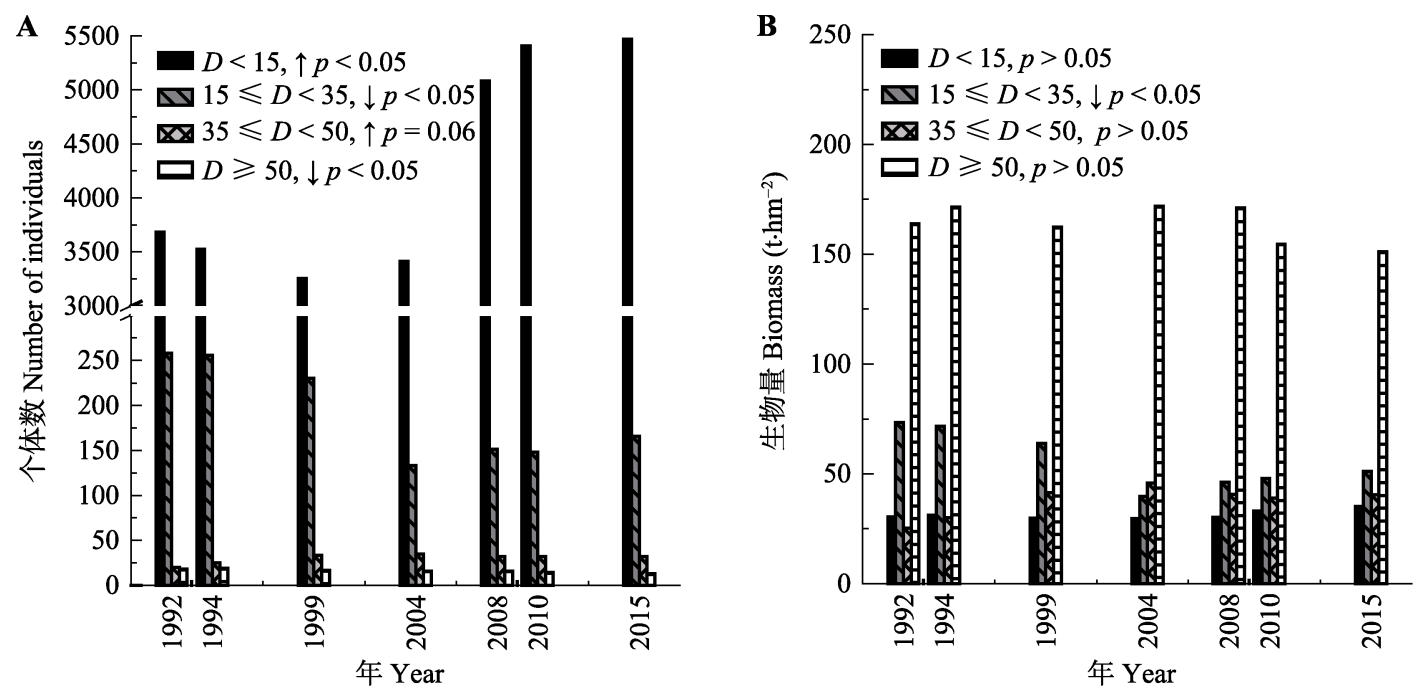

图4 1992-2015年鼎湖山季风林 $1 \mathrm{hm}^{2}$ 样地内群落个体数(A)和生物量(B)的径级结构变化(线性拟合)。 $D$, 胸径; $\uparrow$, 显著 $(p<$ $0.05)$ 上升; $\downarrow$ ，显著 $(p<0.05)$ 下降。

Fig. 4 Dynamics of size class(diameters at breast height) distributions of individuals (A) and biomass (B) from 1992 to 2015 (linear fitting) in the $1 \mathrm{hm}^{2}$ monsoon evergreen broad-leaved forest sample plot. $D$, diameters at breast height; $\uparrow$, significant $(p<0.05)$ increase; $\downarrow$, significant $(p<0.05)$ decrease. 
拉木、云南银柴(Aporosa yunnanensis)、褐叶柄果木 (Mischocarpus pentapetalus)、黄毛榕(Ficus esquiroliana) 和九节(Psychotria asiatica), 其中, 香楠、鼎湖 血桐、柏拉木、褐叶柄果木和黄毛榕个体数分别增 加了1181、890、497、164和60个, 种群依次增大了 8.6倍、16.2倍、1.1倍、2.6倍和7.5倍, 云南银柴和九 节个体数分别减少了 715 个和 228 个, 种群减小 $59.0 \%$ 和 $97.0 \%$ (图5A)。

与1992年比较, 2015 年群落中 29 个主要物种中 有11个中乔木和大乔木树种生物量增量(增加量或 减少量)绝对值超过1992年群落总生物量 $1.0 \%$, 包 括雉、白颜树、肖蒲桃、木荷、窄叶半枫荷 (Pterospermum lanceifolium)、厚壳桂(Cryptocarya chinensis)、橄榄(Canarium album)、白楸、黄果厚 壳桂、观光木(Michelia odora)、黄杞(Engelhardia roxburghiana), 其中, 白颜树、肖蒲桃、窄叶半枫荷、 橄榄、白楸和观光木生物量分别增加了 $16.3 \mathrm{t} 、 3.7 \mathrm{t}$ 、 $7.1 \mathrm{t} 、 3.3 \mathrm{t} 、 3.1 \mathrm{t}$ 和 $4.7 \mathrm{t}$, 种群生物量增大了 $283.8 \%$ 、 $29.6 \% 、 262.0 \% 、 67.2 \% 、 3581.7 \%$ 和 $34.2 \%$, 锥、木 荷、厚壳桂、黄果厚壳桂和黄杞生物量分别减少了 $14.6 \mathrm{t} 、 10.6 \mathrm{t} 、 4.0 \mathrm{t} 、 30.8 \mathrm{t}$ 和 $3.4 \mathrm{t}$, 种群生物量减小 了 $11.0 \% 、 36.4 \% 、 33.5 \% 、 99.6 \%$ 和 $36.6 \%$, 这样的 小乔木和灌木树种有 2 个, 是鼎湖血桐和云南银柴, 鼎湖血桐生物量增加 $4.1 \mathrm{t}$, 增大 $333.7 \%$, 云南银柴

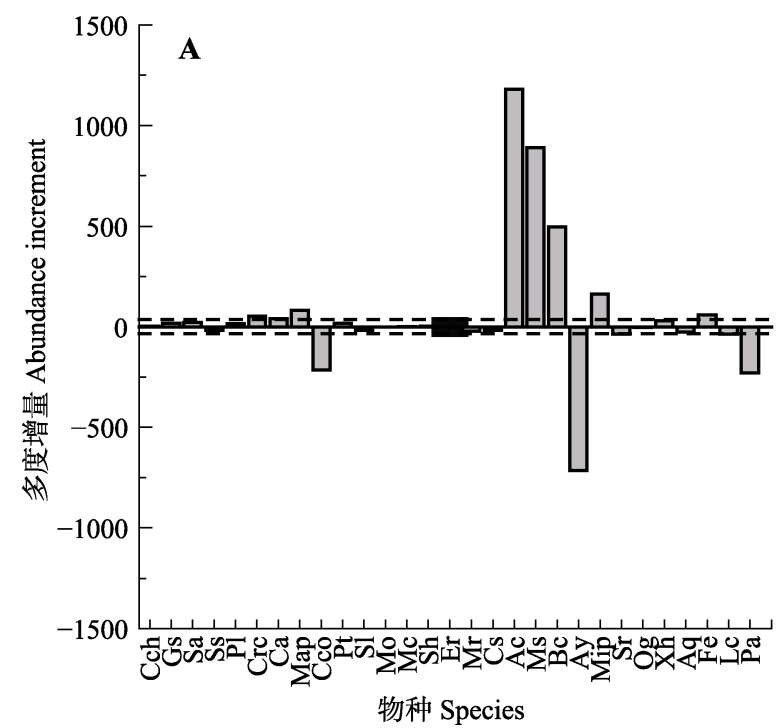

生物量减少 $3.2 \mathrm{t}$, 减小了 $28.0 \%$ (图5B)。

如上所述，1992-2015年雉和木荷生物量下降 (图 5B); 雉各大径级个体数下降, 但有更新个体 $(D B H<10 \mathrm{~cm})$, 种群总个体数略有增加, 木荷 $D B H$ 在 $10-40 \mathrm{~cm}$ 径级个体数下降, $D B H \geqslant 40 \mathrm{~cm}$ 径级个 体数略有增加, 但无更新个体, 种群总个体数下降 $51.4 \% ;$ 在 2015 年雉和木荷生物量分别占群落总生 物量的 $42.4 \%$ 和 $6.6 \%$ 。

\section{3 讨论}

研究结果表明, 1992-2015年鼎湖山季风林总个 体数增加了 $42.7 \%$, 其直接原因是香楠、鼎湖血桐、 柏拉木等少数灌木和小乔木树种种群大小的急剧增 加, 这已经使得群落小个体占据更大比例, 基于个 体数的群落物种多样性降低, 2015年和1992年间基 于个体数的群落差异 ( $\beta$ 多样性指数) 达 $65.6 \%$, 群落 总个体数的变化和物种间多度比例的变化都有很大 贡献, 但总的来说, 群落总个体数和 $\beta$ 多样性指数 在 2008 年以后的增长速率下降, 群落总个体数和物 种-多度分布可能在未来变化较小。而1992-2015年 群落总生物量下降了 $5.1 \%$, 远小于个体数的变化, 虽然雉、木荷、黄果厚壳桂等中乔木和大乔木优势 树种生物量大量减少，但白颜树、窄叶半枫荷等树 种生物量的增加具有部分补偿作用, 这引起了群落

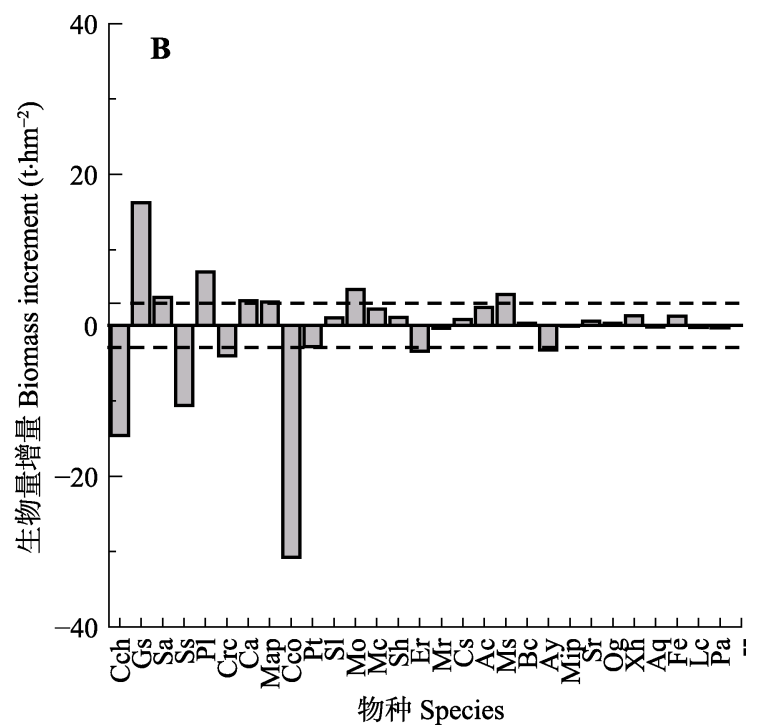

图5 1992和2015年鼎湖山季风林 $1 \mathrm{hm}^{2}$ 样地内 29 个主要物种的多度(A)和生物量(B)变化。A图和 $\mathbf{B}$ 图中的虚线分别为1992年总 个体数的 $1.0 \%(36.4$ 个)和1992年总生物量的 $1.0 \%(2.93 \mathrm{t})$ 。图中各物种代码与物种的对应关系见表 1 。

Fig. 5 The changes in the abundance (A) and biomass (B) of 29 common species in the monsoon evergreen broad-leaved forest (MEBF) sample plot during 1992-2015 in the $1 \mathrm{hm}^{2}$ MEBF sample plot. Dashed lines in plot $\mathbf{A}$ and $\mathbf{B}$ represent $1.0 \%$ of the total individuals (36.4) and biomass (2.93 t) in 1992, respectively. The one-to-one relationship between codes and species is provided in Table 1 . 

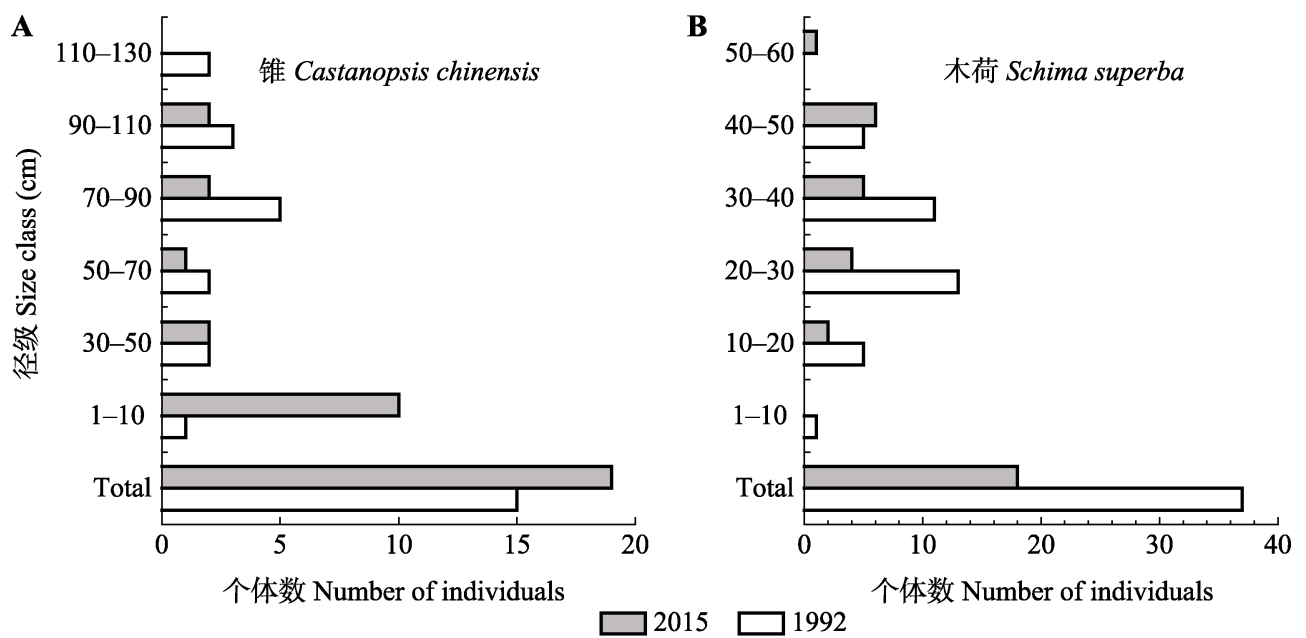

图6 1992和 2015 年鼎湖山季风林 $1 \mathrm{hm}^{2}$ 样地雉 $(\mathbf{A})$ 和木荷 $(\mathbf{B})$ 的种群。Total, 总个体数。

Fig. 6 Population sizes of Castanopsis chinensis (A) and Schima superba (B) between 1992 and 2015 in the $1 \mathrm{hm}^{2}$ monsoon evergreen broad-leaved forest sample plot. Total, total number of individuals.

物种-生物量分布相对更加均匀, 基于生物量的群 落物种多样性增大, 2015年和1992年间基于生物量 的群落差异 ( $\beta$ 多样性指数)为 $37.4 \%$, 其中与总生物 量的变化相比, 物种间生物量比例变化更加剧烈, 贡献了群落差异的 $89.0 \%$, 群落总生物量和 $\beta$ 多样性 指数在1992-2015年一直呈线性变化趋势, 未来群 落生物量总量和组成可能继续变化。

鼎湖山季风林是演替近顶极群落, 该地区森林 群落的演替顺序为马尾松林, 马尾松、雉和木荷等 树种为主的针阔混交林, 季风林 (王伯荪和彭少麟, 1985), 所以季风林中的阳生性树种雉和木荷主要 是演替上一阶段针阔混交林时期的遗留(彭少麟和 方炜, 1995; 彭少麟等, 1998), 锥和木荷种群小, 大 个体逐渐死亡, 少或无更新个体, 但季风林中的雉 和木荷多为大个体, 2015 年两个树种生物量之和仍 占群落总生物量的 $49.0 \%$, 所以雉和木荷在鼎湖山 季风林生态系统功能中仍发挥重要作用, 但其个体 不断死亡将给群落造成巨大波动(彭闪江等, 2003; 张池等, 2006), 甚至群落总生物量持续下降。而在 气候变化背景下, 群落内大径级个体更容易受到干 旱胁迫(Bennett et al., 2015), 因此气候变化可能会 加快鼎湖山季风林内锥和木荷种群的衰退, 影响群 落的演替进程(王纪军和裴铁璠, 2004)。

随着向气候顶极群落演替, 中生性的乔木树种 黄果厚壳桂和厚壳桂将成为季风林中的优势物种 (彭少麟和李丹, 1999), 1992年黄果厚壳桂和厚壳桂 生物量之和占群落总生物量的 $14.6 \%$, 到2015年其 生物量只占 $2.9 \%$, 它们的优势度下降和虫害爆发有
关。黄忠良(2000)在鼎湖山季风林 8 年的调查研究, 发现樟翠尺蛾(Thalassodes quadraia)种群爆发对群 落内包括黄果厚壳桂和厚壳桂在内的樟科植物造成 了极大破坏, 并且分析发现虫害爆发和降水量及降 水格局变化有密切关系; 张池等(2006)对鼎湖山季 风林1992-2004年树木个体死亡动态进行了研究, 认为樟翠尺蛾的持续爆发导致了该群落 $90 \%$ 以上的 黄果厚壳桂个体死亡。陈志成和万贤崇(2016)认为 气候变化提高了虫害的爆发频度, 虫害对森林的危 害加重; Clark等(2016)同样发现由干旱及其伴随的 虫害改变了美国森林群落的结构和生物多样性。在 华南地区降水变率增大的背景下(Zhou et al., 2011), 虫害发生与气候变化等的关系及其对季风林的危害 程度还需要深入研究。

近10年来, 有关全球环境变化对森林群落结构 影响的研究和讨论有很多, 变暖和降水减少(或降 水变率加大)诱导的干旱对森林造成影响, 中国亚 热带地区面临同样的环境问题, 研究认为气温升高 和降水变率增大减少了土壤水分(Zhou et al., 2011; 刘效东等, 2014), 并诱导了季风林树木死亡率和更 新率的上升(Zhou et al., 2013), 亚热带常绿阔叶林 群落个体数及其组成变化(Zhou et al., 2014); Li等 (2015)通过测定植物的功能, 发现季风林群落中具 有与抗旱和快速生长相关功能性状的物种香楠、鼎 湖血桐、柏拉木等多度增加, 同样认为气候变干已 经引起该森林群落结构变化。该群落的研究结果与 McIntyre等(2015)在美国整个加利福尼亚地区森林 长达70年的研究结果一致, 他们也发现群落大径级 
个体下降，小径级个体增加，导致林分密度增加了 $30 \%$, 基面积下降了 $19 \%$, 而橡树逐渐取代松树的 优势地位, 并认为群落结构改变与该地区气温上升 和水分胁迫有关。但也有许多研究认为干旱会同时 降低群落个体数和生物量(Allen et al., 2015), 而 Zhang等(2015)研究了加拿大西部地区森林长达50 年的群落结构动态变化, 认为气候变化并不是主要 因素, 气候变化下群落内部的竞争关系变化才是引 起群落结构变化的主要原因。

\section{4 结论}

通过以上分析, 我们得到以下主要结论：1)从 1992到2015年该森林群落林分密度增加了 42.7\%, 生物量减少了 $5.1 \%$, 与 1992 年相比, 基于 $\beta$ 多样性 指数的群落生物量差异为 $37.4 \%$, 主要原因是群落 内物种生物量分配的变化, 而群落个体差异则高达 $65.6 \%$, 群落总个体数变化和群落内物种个体数分 配的改变都有很大贡献; 2)小乔木和灌木个体数剧 增, 生物量增大, 中乔木和大乔木个体数变化不显 著, 但生物量显著下降; 3$)$ 小径级 $(D B H<15 \mathrm{~cm})$ 个 体数呈显著增加趋势, 其他径级个体数也有显著变 化, 但各径级生物量变化基本不显著; 4)香楠、鼎湖 血桐、柏拉木等物种个体数急剧增加, 锥、木荷、 黄果厚壳桂等树种生物量大量减少, 白颜树、窄叶 半枫荷等树种生物量增加, 这些物种是群落结构变 化的主要贡献者。鼎湖山季风林群落结构在 1992-2015年发生了巨大变化, 可能与演替进程、虫 害和气候变化等因素的影响有关。但我们对季风林 的演替进程, 季风林如何响应环境变化, 演替进程 与气候变化间的相互作用, 虫害爆发和气候的关系 等问题的了解不多, 也缺乏季风林群落结构改变对 其生态系统服务功能影响的研究, 未来需要对这些 问题进行深入研究, 加强对我国季风林的监测和 管理。

致谢 感谢参与鼎湖山季风常绿阔叶林群落历年群 落调查的老师和同学。

\section{参考文献}

Allen CD, Breshears DD, McDowell NG (2015). On underestimation of global vulnerability to tree mortality and forest die-off from hotter drought in the Anthropocene. Ecosphere, 6, 1-55.

Allen CD, Macalady AK, Chenchouni H, Bachelet D, McDowwww.plant-ecology.com ell N, Vennetier M, Kitzberger T, Rigling A, Breshears DD, Hogg EH, Gonzalez P, Fensham R, Zhang Z, Castro J, Demidova N, Lim JH, Allard G, Running SW, Semerci A, Cobb N (2010). A global overview of drought and heatinduced tree mortality reveals emerging climate change risks for forests. Forest Ecology and Management, 259, 660-684.

Anderegg WRL, Hicke JA, Fisher RA, Allen CD, Aukema J, Bentz B, Hood S, Lichstein JW, Macalady AK, McDowell N, Pan YD, Raffa K, Sala A, Shaw JD, Stephenson NL, Tague C, Zeppel M (2015). Tree mortality from drought, insects, and their interactions in a changing climate. New Phytologist, 208, 674-683.

Anderegg WRL, Klein T, Bartlett M, Sack L, Pellegrini AFA, Choat B, Jansen S (2016). Meta-analysis reveals that hydraulic traits explain cross-species patterns of droughtinduced tree mortality across the globe. Proceedings of the National Academy of Sciences of the United States of America, 113, 5024-5029.

Bennett AC, McDowell NG, Allen CD, Anderson-Teixeira KJ (2015). Larger trees suffer most during drought in forests worldwide. Nature Plants, 1, 15139. DOI: 10.1038/nplants. 2015.139.

Chen TG, Zhang JT (1999). A comparison of fifteen species diversity indices. Henan Science, 17, 62-64, 78. [陈廷贵, 张金屯 (1999). 十五个物种多样性指数的比较研究. 河 南科学, 17, 62-64, 78.]

Chen ZC, Wan XC (2016). The relationship between the reduction of nonstructural carbohydrate induced by defoliatorand the growth and mortality of trees. Chinese Journal of Plant Ecology，40，958-968. [陈志成，万贤崇 (2016). 虫害叶损失造成的树木非结构性碳减少与树木生长、死 亡的关系研究进展. 植物生态学报, 40, 958-968.]

Clark JS, Iverson L, Woodall CW, Allen CD, Bell DM, Bragg DC, D'Amato AW, Davis FW, Hersh MH, Ibanez I, Jackson ST, Matthews S, Pederson N, Peters M, Schwartz MW, Waring KM, Zimmermann NE (2016). The impacts of increasing drought on forest dynamics, structure, and biodiversity in the United States. Global Change Biology, 22, 2329-2352.

Ding SY, Song YC (2004). Research advances in vegetation dynamic of evergreen broad-leaved forest. Acta Ecologica Sinica, 24, 1769-1779. [丁圣彦, 宋永昌 (2004). 常绿阔 叶林植被动态研究进展. 生态学报, 24, 1769-1779.]

Fang YT, Gundersen P, Vogt RD, Koba K, Chen FS, Chen XY, Yoh M (2011). Atmospheric deposition and leaching of nitrogen in Chinese forest ecosystems. Journal of Forest Research, 16, 341-350.

Fekete I, Lajtha K, Kotroczo Z, Varbiro G, Varga C, Toth JA, Demeter I, Veperdi G, Berki I (2017). Long-term effects of climate change on carbon storage and tree species composition in a dry deciduous forest. Global Change Biology, 
23, 3154-3168.

Frank D, Reichstein M, Bahn M, Thonicke K, Frank D, Mahecha MD, Smith P, van der Velde M, Vicca S, Babst F, Beer C, Buchmann N, Canadell JG, Ciais P, Cramer W, Ibrom A, Miglietta F, Poulter B, Rammig A, Seneviratne SI, Walz A, Wattenbach M, Zavala MA, Zscheischler J (2015). Effects of climate extremes on the terrestrial carbon cycle: Concepts, processes and potential future impacts. Global Change Biology, 21, 2861-2880.

Guariguata MR, Ostertag R (2001). Neotropical secondary forest succession: Changes in structural and functional characteristics. Forest Ecology and Management, 148, 185-206.

Huang ZL (2000). The Interactions of population dynamics of Thalassodes quadraria and the plant community structure and climate factors in Dinghushan. Chinese Journal of Ecology, 19, 24-27, 31. [黄忠良 (2000). 樟翠尺蛾种群 动态与植物群落结构及气候因子的关系. 生态学杂志, 19, 24-27, 31.]

Huang ZL, Kong GH, Wei P (1998). Plant species diversity dynamics in Dinghu Mountain forests. Biodiversity Science, 6, 116-121. [黄忠良, 孔国辉, 魏平 (1998). 鼎湖 山植物物种多样性动态. 生物多样性, 6, 116-121.]

Jayakaran AD, Williams TM, Ssegane H, Amatya DM, Song B, Trettin CC (2014). Hurricane impacts on a pair of coastal forested watersheds: Implications of selective hurricane damage to forest structure and streamflow dynamics. Hydrology and Earth System Sciences, 18, 1151-1164.

Li RH, Zhu SD, Chen HYH, John R, Zhou GY, Zhang DQ, Zhang QM, Ye Q (2015). Are functional traits a good predictor of global change impacts on tree species abundance dynamics in a subtropical forest? Ecology Letters, 18, 1181-1189.

Liu XD, Zhou GY, Chen XZ, Zhang DQ, Zhang QM (2014). Forest microclimate change along with the succession and response to climate change in south subtropical region. Acta Ecologica Sinica, 34, 2755-2764. [刘效东, 周国逸, 陈修治, 张德强, 张倩媚 (2014). 南亚热带森林演替过 程中小气候的改变及对气候变化的响应. 生态学报, 34, 2755-2764.]

McIntyre PJ, Thorne JH, Dolanc CR, Flint AL, Flint LE, Kelly M, Ackerly DD (2015). Twentieth-century shifts in forest structure in California: Denser forests, smaller trees, and increased dominance of oaks. Proceedings of the National Academy of Sciences of the United States of America, 112, 1458-1463.

Pan Y, Birdsey RA, Fang J, Houghton R, Kauppi PE, Kurz WA, Phillips OL, Shvidenko A, Lewis SL, Canadell JG, Ciais P, Jackson RB, Pacala SW, McGuire AD, Piao S, Rautiainen A, Sitch S, Hayes D (2011). A large and persistent carbon sink in the world's forests. Science, 333, 988-993.
Peng SJ, Huang ZL, Zhou GY, Zhou XY, Zhang C, He WQ (2003). Gap formation characteristics and its effects on sapling composition and diversity in Dinghushan Biosphere Reserve. Journal of Tropical and Subtropical Botany, 11，229-235. [彭闪江, 黄忠良, 周国逸, 周小勇, 张池, 贺握权 (2003). 鼎湖山林窗形成特征及其对幼树 组成和多样性的影响. 热带亚热带植物学报, 11, 229235.]

Peng SL, Fang W (1995). Studies on the dynamic of Castanopsis chinensis and Schima superba population in forest succession of Dinghushan Mountain. Acta Phytoecologica Sinica, 19, 311-318. [彭少麟, 方炜 (1995). 鼎湖山植被 演替过程中椎栗和荷木种群的动态. 植物生态学报, 19 , 311-318.]

Peng SL, Fang W, Ren H, Huang ZL, Yu QF, Zhang DQ (1998). The dynamics on organization in the successional process of Dinghushan Cryptocarya. Acta Phytoecologica Sinica，22，245-249. [彭少麟，方炜，任海, 黄忠良, 孔 国辉, 余清发, 张德强 (1998). 鼎湖山厚壳桂群落演替 过程的组成和结构动态. 植物生态学报, 22, 245-249.]

Peng SL, Li D (1999). The ecological characteristics of Cryptocarya concinna population. Acta Ecologica Sinica, 19, 485-489. [彭少麟, 李丹 (1999). 黄果厚壳桂种群生 态学特征. 生态学报, 19, 485-489.]

Song YC (2001). Vegetation Ecology. East China Normal University Press, Shanghai. [宋永昌 (2001). 植被生态学. 华东师范大学出版社, 上海.]

Trumbore S, Brando P, Hartmann H (2015). Forest health and global change. Science, 349, 814-818.

Wang BS, Peng SL (1985). Analysis on the forest communities of Dinghushan V. Linear system of the community succession. Acta Scientiarum Naturalium Universitatis Sun Yat-Sen, (4), 75-80. [王伯䔉, 彭少麟 (1985). 鼎湖山森 林群落分析 V. 群落演替的线性系统与预测. 中山大学 学报(自然科学版), (4), 75-80.]

Wang JJ, Pei TF (2004). Effects of climate change on forest succession. Chinese Journal of Applied Ecology, 15, 1722-1730. [王纪军, 裴铁璠 (2004). 气候变化对森林 演替的影响. 应用生态学报, 15, 1722-1730.]

Wehner CE, Stednick JD (2017). Effects of mountain pine beetlekilled forests on source water contributions to streamflow in headwater streams of the Colorado Rocky Mountains. Frontiers of Earth Science, 11, 496-504.

Wen DZ, Wei P, Kong GH, Zhang QM, Huang ZL (1997). Biomass study of the community of Castanopsis chinensis + Cryptocarya concinna + Schima superba in a southern China reserve. Acta Ecologica Sinica, 19, 497-504. [温达 志, 魏平, 孔国辉, 张倩媚, 黄忠良 (1997). 鼎湖山雉 栗+黄果厚壳桂+荷木群落生物量及其特征. 生态学报, 19, 497-504.]

Xiao Q, Xiao Y, Ouyang ZY, Xu WH, Xiang S, Li YZ (2014). Value assessment of the function of the forest ecosystem 
services in Chongqing. Acta Ecologica Sinica, 34, 216223. [肖强, 肖洋, 欧阳志云, 徐卫华, 向轼, 李勇志 (2014). 重庆市森林生态系统服务功能价值评估. 生态 学报, 34, 216-223.]

Xiao Y, Zhou GY, Zhang QM, Wang WT, Liu SZ (2014). Increasing active biomass carbon may lead to a breakdown of mature forest equilibrium. Scientific Reports, 4, 3681. DOI: 10.1038/srep03681.

Xiong X, Zhang HL, Wu JP, Chu GW, Zhou GY, Zhang DQ (2016). ${ }^{13} \mathrm{C}$ and ${ }^{15} \mathrm{~N}$ isotopic signatures of plant-soil continuum along a successional gradient in Dinghushan Biosphere Reserve. Chinese Journal of Plant Ecology, 40, 533-542. [熊金金, 张慧玲, 吴建平, 褚国伟, 周国逸, 张 德强 (2016). 鼎湖山森林演替序列植物-土壤碳氮同位 素特征. 植物生态学报, 40, 533-542.]

Ye WH, Cao HL, Huang ZL, Lian JY, Wang ZG, Li L, Wei SG, Wang ZM (2008). Community structure of a $20 \mathrm{hm}^{2}$ lower subtropical evergreen broadleaved forest plot in Dinghushan, China. Journal of Plant Ecology (Chinese Version), 32, 274-286. [叶万辉, 曹洪麟, 黄忠良, 练琚 愉, 王志高, 李林, 魏识广, 王章明 (2008). 鼎湖山南 亚热带常绿阔叶林 20 公顷样地群落特征研究. 植物生 态学报, 32, 274-286.]

Zhang C, Huang ZL, Shi JH, Li L, Wei SG, Li J (2006). Dynamics and causes of woody plant death in the monsoon evergreen broad-leaved forest in Dinghushan Nature Reserve. Acta Ecologica Sinica, 26, 2457-2462. [张池, 黄忠 良, 史军辉, 李林, 魏识广, 李昫 (2006). 鼎湖山季风 常绿阔叶林木本植物个体死亡动态. 生态学报, 26, 2457-2462.]

Zhang J, Huang S, He F (2015). Half-century evidence from western Canada shows forest dynamics are primarily driven by competition followed by climate. Proceedings of the National Academy of Sciences of the United States of America, 112, 4009-4014.

Zhang Y, Chen HYH (2015). Individual size inequality links forest diversity and above-ground biomass. Journal of Ecology, 103, 1245-1252.

Zhang YM, Zhou GY, Wen DZ, Zhang DQ, Zhang QM (2003). Dynamics of the Castanopsis chinensis-Schima superbaCryptocarya concinna community of monsoon evergreen broadleaved forest in Dinghushan Nature Reserve in lower subtropical China. Acta Phytoecologica Sinica, 27, 256-262. [张咏梅, 周国逸, 温达志, 张德强, 张倩媚 (2003). 南亚热带季风常绿阔叶林雉栗-荷木-黄果厚壳 桂群落发展趋势探讨. 植物生态学报, 27, 256-262.]

Zhou GY, Houlton BZ, Wang WT, Huang WJ, Xiao Y, Zhang QM, Liu SZ, Cao M, Wang XH, Wang SL, Zhang YP, Yan JH, Liu JX, Tang XL, Zhang DQ (2014). Substantial reorganization of China's tropical and subtropical forests: Based on the permanent plots. Global Change Biology, 20, 240-250.

Zhou GY, Peng CH, Li YL, Liu SZ, Zhang QM, Tang XL, Liu JX, Yan JH, Zhang DQ, Chu GW (2013). A climate change-induced threat to the ecological resilience of a subtropical monsoon evergreen broad-leaved forest in Southern China. Global Change Biology, 19, 1197-1210.

Zhou GY, Wei XH, Wu YP, Liu SG, Huang YH, Yan JH, Zhang DQ, Zhang QM, Liu JX, Meng Z, Wang CL, Chu GW, Liu SZ, Tang XL, Liu XD (2011). Quantifying the hydrological responses to climate change in an intact forested small watershed in Southern China. Global Change Biology, 17, 3736-3746.

责任编委: 李意德 责任编辑: 王 蒇 